\title{
Immunomodulatory Effects of Papain in Patients with Cervical Ectopies
}

\author{
Dilorom Musakhodjaeva ${ }^{1}$, Nikadam Nuraliev ${ }^{1}$, Nigora Fayzullaeva ${ }^{1}$, Maruf Uyldashev ${ }^{1}$, \\ Rano Sabitova ${ }^{1}$, Gulnara Yangieva ${ }^{2}$ \\ ${ }^{1}$ Immunomorphology DPT, Institute of Immunology, Academy of Science, Uzbekistan \\ ${ }^{2}$ Department of Obstetrics and Gynecology, Tashkent Medical Academia, Uzbekistan
}

\begin{tabular}{l} 
Article Info \\
\hline Article history: \\
Received Jun 28, 2013 \\
Revised Dec 20, 2013 \\
Accepted Apr 26, 2014 \\
\hline
\end{tabular}

Keyword:

Cervical ectopies

Cytokines

Enzyme

Herbal

Papain

\begin{abstract}
The study detected that in patients with cervical ectopia production of cytokines (TNF $\alpha$, IL-4 и IL-10) was significantly altered. The degree of change depended on the presence or absence of infection. Conducted therapy with herbal enzyme - papain contributed to the cupping of inflammation and normalization of the concentration of the studied cytokines.
\end{abstract}

Corresponding Author:

Rano Sabitova, Institute of Immunology, Uzbekistan Academy of Science, 74 Yahyo Gulyamov, Tashkent 100060, Uzbekistan.

Email: ranosabitova@yahoo.com

\section{INTRODUCTION}

History of the study of cervical ectopia (CE) goes back to a century, but in recent decades, this problem has attracted increasing attention. This disease occurs in 10-15\% of young women and teenage girls, and has negative impact on reproductive health. Most ectopic and other pathological changes in the cervix are recorded in conjunction with sexually transmitted infections [1],[2].

Changes in the vaginal environment and abnormal condition of the surface layers of cervical epithelium facilitate the penetration of viruses into cells. In this connection special importance takes infection with human papilloma virus (HPV), because the persistence of its oncogenic types may lead to intraepithelial neoplasia and cancer, particularly cervical cancer. Infection with pathogens popillomo-virus infection (PVI) and the likelihood of subsequent development of disease is largely determined by the immune status of the organism. In turn, the viruses themselves initiate the formation of immune deficiency that leads to prolonged persistence of the pathogen in the patient and the recurrence of the disease [3],[4].

Mediators of the immune response - cytokines: interleukin-2 and gamma interferoA play a certain role in the pathogenesis of cervical ectopias, they are proinflammatory and able to limit tumor growth, and cytokines interleukin-4 and interleukin-10 are anti-inflammatory cytokines and, therefore, can stimulate tumor growth $[2],[3],[6]$.

Treatment of cervical erosion can be radical and conservative. To improve the quality it is necessary to consider the initial state of immunity, concomitant somatic pathology, the presence of mixed or combined urogenital infections, as well as the localization of the pathological process [4],[5],[7]. 
In connection with the above, the purpose of this study was to investigate the local level of pro-and anti-inflammatory (TNF $\alpha$, IL-4 and IL-10) cytokines in women with cervical ectopia in the dynamics of treatment with the enzyme of plant origin - papain.

\section{RESEARCH METHOD}

We have conducted clinical and laboratory examination of 124 women of reproductive age who have applied for examinations in the third clinic in Tashkent Medical Academy (TMA) and included: medical history, gynecological examination, colposcopy, bacterioscopic study of vaginal discharge, survey on sexually transmitted infections (polymerase chain reaction, ELISA, bacteriological examination of vaginal secretions).

18 healthy women were in control group. The study included determination of immune status level in the vaginal discharge of interleukin (TNF $\alpha$, IL-4 and IL-10) using reagent kits «Cytokine" Ltd. Saint-Petersburg before and after treatment.

Immunological studies were conducted at the Institute of Immunology, Academy of Sciences of Republic of Uzbekistan. Mathematical processing of data was carried out by methods of variation statistics using standard mathematical software packages with the definition of average, its errors, Student's t test.

\section{RESULTS AND ANALYSIS}

Age of our patients ranged from 18 to 38 years, average age was $23,7 \pm 0,66$ years. The diagnosis of "cervical ectopy" was first set in 96 women. A survey in 31 patients revealed a human papilloma virus (HPV). The dominant position (51.6\%) held the 16 type, which corresponds to the data of other researchers. HPV 18 was found in 7 cases $(22.6 \%), 31$ in 5 (16.1\%), 33 type-3 (9.7\%).

The age of patients with a history of HPV showed that $36.1 \%$ of women were in the age of $20,29.7 \%$ 21-25 years, $19.8 \%$ - 26-30 years, 14.4\% - 31-35 years old. It was observed that with increasing age of the observed decrease in the incidence of HPV in patients with ectopia of the cervix.

To analyze the results of treatment patients were divided into three groups: I group (28 women) received conventional treatment: vaginal cleansing and chemical coagulation Solkovagina; II group (42 patients) - received combined therapy (vaginal cleansing and chemical coagulation and candles Solkovagina proktozan) . Group III-(54 women) received combined therapy: Vaginal, diathermocoagulation, hormonal contraception, and 5 days after coagulation - vaginal applique plant enzyme papain for 7-8 days.

The survey was conducted before treatment, at the end of therapy and after the next menstrual period. At the time of treatment was recommended the exclusion of sexual life, and then - barrier contraception for the period of observation and control tests.

The dominance of Th1 cytokines is associated with viral load. However, several authors demonstrated that the inflammatory process in the cervix may involve the simultaneous increase in the level of Th1 and Th2 cytokines [2].

We investigated the levels of cytokines in the vaginal secretions of women, depending on the presence or absence of HPV in cervical ectopy.

As can be seen from Figure 1, the level of the studied cytokines was significantly different from the control group. Thus, the product $\mathrm{TNF} \alpha$, which belongs to the cytokine with direct antiviral activity and is produced by NK - cells in patients with $\mathrm{CE}$ was 1.25 times higher than in the control group (P>0.05). And in the group of patients with CE and HPV - 1.7 times higher than that of women in the control group (P>0.01). Identification of an increase in vaginal secretions level of TNF $\alpha$ shows the development of local inflammation. It should be noted that increased levels of TNF $\alpha$ with ectopia among women against cervical HPV detected in $63 \%$ of cases (an average of $42,3 \pm 2,8$ vs. $24,6 \pm 0,5 \mathrm{pg} / \mathrm{ml}$ in controls, $\mathrm{P}>0,01$ ), whereas among women with cervical ectopia without HPV in $38 \%(31,02 \pm 2,6 \mathrm{pc} / \mathrm{ml}, \mathrm{P}>0.05)$. 


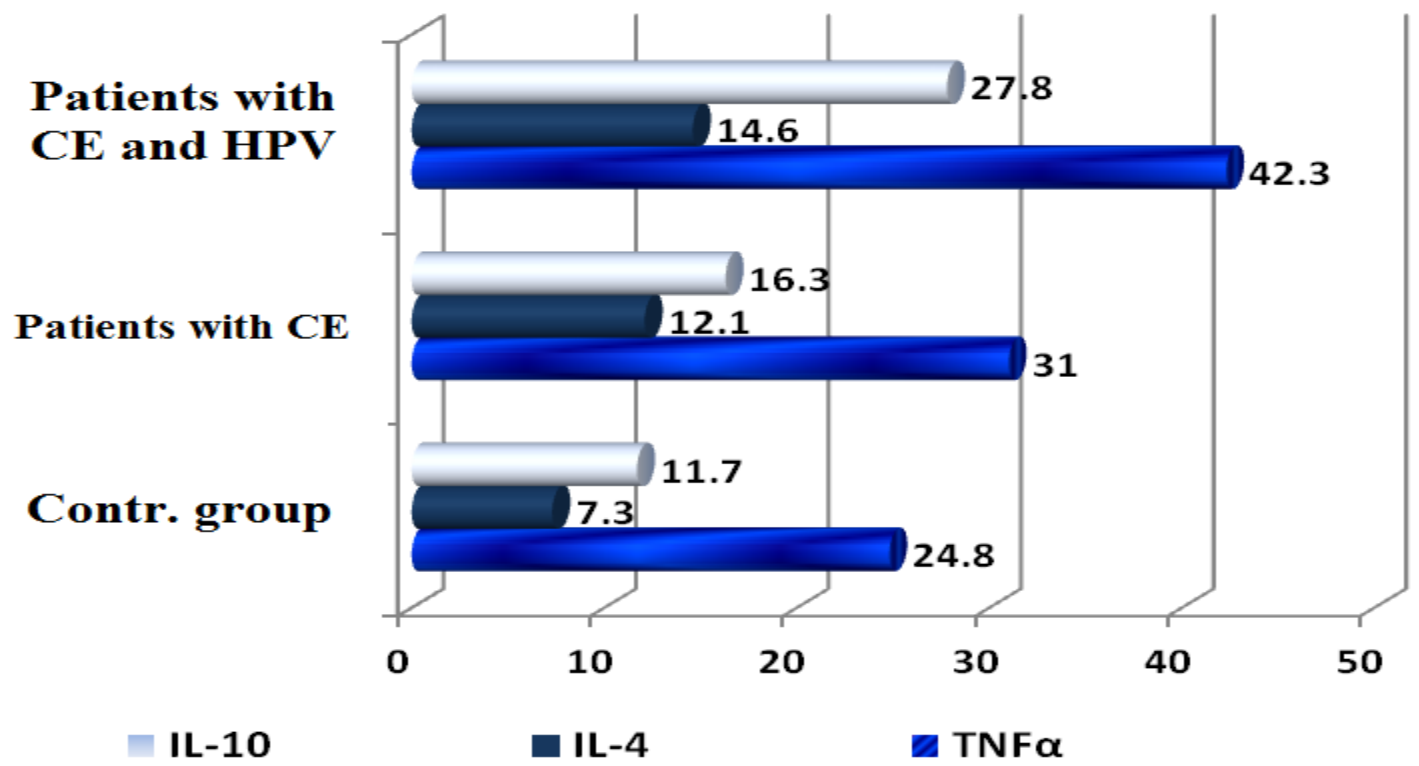

Figure 1. Dynamics of cytokine levels in vaginal fluid of women surveyed $(\mathrm{pg} / \mathrm{ml})$

As a result of the release of TNF $\alpha$, capillary permeability is increased, vascular endothelium is damaged, intravascular thrombosis arised. In addition, TNF $\alpha$, performing killing of cells infected with the virus, thus causing viremia and infection of new lymphocytes. Our results confirmed by literature data show that the expression of this cytokine induces viruses. At the same time high concentrations of this cytokine may increase inflammation, and run the activation mechanisms of apoptosis.

At the same time, we studied the levels of inflammatory cytokines - IL- 4 and IL-10 in the vaginal secretions of women with cervical ectopia. The level of interleukins had been elevated control values. Moreover, women with ectopia of the cervix and HPV had levels of IL-4 higher than control values at 1.66 times $(\mathrm{P}>0.01)$. IL-4 is produced predominantly by T lymphocytes belonging to the Th2 subset. The main function of IL-4 - is the control of proliferation, differentiation and function of B-lymphocytes, ie antibody response. IL-4 reduces the expression of FcR of all types, thus inhibiting antibody-dependent cytotoxicity. IL-4 blocks the production of proinflammatory cytokines, while increasing the production of G-CSF and M-C'SF, as well as the production of superoxide radicals and PGE2, and also stimulates the production of PAF. It has a local anti-tumor activity. Its elevated levels observed in many inflammatory processes in the organism [5].

Analysis of the results of the study the level of IL-10 showed it increased in women with ectopia of the cervix, which on average amounted to $16,3 \pm 1,0 \mathrm{pg} / \mathrm{ml}(\mathrm{P}>0.05)$, but in women with CE against HPV levels of IL-10 was 2.4 times higher than in the control group $(\mathrm{P}>0.001)$ and 1.7 times higher than in women with CE ( $\mathrm{P}>0.05)$. It is known that the activity of IL-10 is usually associated with the suppression of antiviral immunity, leading to chronic disease [2].

In such a way in all groups of women with CE revealed an increased synthesis of cytokines, but increasing severity depended on the extent of lesions of the cervix. It is precisely this inability to develop a balanced pro-inflammatory cytokines seem to play a significant role in the maintenance or progression of the $\mathrm{CE}$ and determines the characteristics of organisms that support the inflammatory process. The results of studies conducted after the treatment showed that the treatment with papain the healing was observed for 14 days, whereas with traditional therapy and comparison group on the 30th day. In addition to the clinical effect (reduction of emissions after coagulation, the absence of pain), Colposcopic picture of the regeneration of the cervix was more pronounced in the combined therapy. Analysis of repeated study of cytokine levels in patients with ectopia of the cervix after treatment showed that all treatments had an impact on the concentration of the studied cytokines. There have been some changes. However, the most pronounced changes were observed in the complex therapy with papain.

As can be seen from Table 1, there was a tendency to decrease the level of TNF $\alpha$ in the group of patients receiving standard treatment (group 1). And the women in group 2 who received combined therapy (vaginal cleansing and chemical coagulation and candles Solkovagina proktozan TNF $\alpha$ concentrations decreased 
by 1.2 times $(\mathrm{P}<0.05)$, whereas in women receiving combined therapy with the inclusion of papain $\mathrm{TNF} \alpha$ decreased by 1.3 times $(\mathrm{P}<0,05)$.

Table 1. Dynamics of cytokine levels in the vaginal secretions of surveyed women $(\mathrm{M} \pm \mathrm{m})$

$\begin{array}{cccccc}\text { Cytokines, } & \text { Contr. Group } & \begin{array}{c}\text { Before } \\ \text { treatment }\end{array} & \text { Group 1 } & \text { Group 2 } & \text { Group 3 } \\ \mathrm{pg} / \mathrm{ml} & 24,8 \pm 1,2 & 31,0 \pm 1,6^{*} & 30,7 \pm 1,5^{*} & 29,1 \pm 0,9^{* \wedge} & 26,3 \pm 1,1^{* \wedge} \\ \mathrm{TNF} \alpha & 7,3 \pm 0,6 & 13,5 \pm 0,8^{*} & 11,2 \pm 0,7^{*} & 10,3 \pm 0,8^{* \wedge} & 9,4 \pm 0,7^{* \wedge} \\ \text { IL-4 } & 11,7 \pm 0,8 & 23,7 \pm 1,1^{*} & 21,6 \pm 1,1^{*} & 19,2 \pm 1,0^{* \wedge} & 14,9 \pm 0,8^{* \wedge} \\ \text { IL-10 } & & \end{array}$

Note:* - the difference is clear and significant to the control group

$\wedge$ - the difference is clear and significant to group before treatment

$(\mathrm{P}<0,05-0,001)$

In all groups, one month after treatment was observed reduction of anti-inflammatory cytokines (IL-4 and IL-10). In the Ist group the change in concentration of IL-4 and IL-10 was not significant. This ratio is likely to indicate a lack of effective therapy and may be a predisposing factor for the development of recurrent disease. While in the group of patients in whom treatment was connected with Papain,, there was a significant reduction in inflammatory cytokines $(\mathrm{P}<0,01)$.

Implementation of control clinical and laboratory examinations, which included detection of HPV and colposcopy showed that in group III, HPV is found in 2 patients, ie the effectiveness of therapy was $93.5 \%$. In Group II there were 9 positive samples, the efficiency - 71.8\%.With colposcopy complete epithelialization of the wound surface was observed in 28 patients of group III and 25 - II group. Repeated destruction of the ectopic sites was carried out to one patient in Group III and 5 - in group II.

\section{CONCLUSION}

Therefore, treatment of cervical ectopy with topical papain in the complex therapy is pathogenetically justified and highly promising. Combined therapy has significant anti-inflammatory and immunomodulatory effects, contributes to the acceleration of reparative processes.

\section{REFERENCES}

[1] Borzenko E. V., Simkina T. V., "The effectiveness of the method of argon-plasma coagulation for treatment of benign diseases of the cervix", Proceedings of the Russian National Congress "Man and medicine. Ural 2007, in the Journal of Medical Science and Education of the Urals, 2007.

[2] Kashuba E. A., Borzenko E. V., Kurlovich N. A., "Spontaneous and stimulated production of cytokines of cervical secretions in women with abnormal cervical", Proceedings of the International Congress of Rehabilitation Medicine and immunorehabilitation, in the journal Allergy and Immunology, 2009.

[3] Borzenko E. V., Chernecova L. F., Kashuba E. A., "The role of inflammation in the pathogenesis of diseases of the cervix," Proceedings of the international conference Prevention of cervical cancer; look into the future, 2008.

[4] Prilepskaya V. N., Rudakova E. B., Kononov A. V., "Ectopia and cervical erosion”, MED press, pp. 175, 2002.

[5] Yuryev S. Yu., Chernecova N. A., Kurlovich N. A., Borzenko E. V., "Immunological parameters of cervical secretions in patients with ectopia of the cervix with concomitant genital infection pathology", Medical Science and Education of the Urals, pp. 14-17, 2009.

[6] Cauci S., Guaschino S., Driussi S., et al., J Infect Dis, pp. 1614-1620, 2002.

[7] Shaykov K. L., "Status of local immunity of the cervix in inflammatory diseases of the pelvic organs and methods of its correction by kipferon immunomodulator: Abstract", thesis, Candidat of medical sciences, pp. 24, 2004. 


\section{BIOGRAPHIES OF AUTHORS}
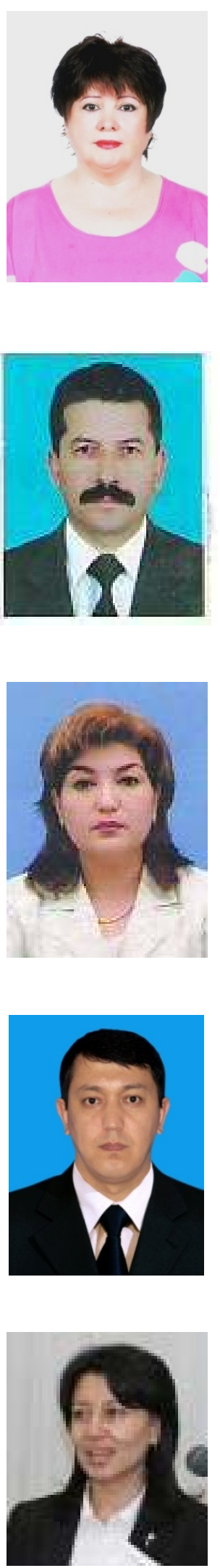

Dilorom Musakhodjaeva, Doctor of Biological Science is the Chief of the Immunomorphology DPT of the Institute of Immunology, Uzbekistan's Academy of Science. Her scientific interests are in the fundamental and applied immunology, immunophisiology, immune mechanisms of inflammation, developing tumors and ophalmic diseases, endocrinology, reproductive and pediatric immunology as well.

Phone: +998 712330113 (of)

e-mail: dilym@xnet.uz

Dr. Nikadam Nuraliev, MD, Doctor of Medical Science, is a member of the Immunomorphology DPT study team. He has scientific interests in the fundamental and applied immunology as well. Together with the scientific work he is engaged in the teaching work within Tashkent Medical Academia.

Dr. Nigora Fayzullaeva, MD, Candidate of Medical Science, the member of the Immunomorphology Depertment study team and immunologist with number of years with clinical and scientific experience. Her scientific interests in clinical immunology, especially in maternal and child health

Dr. Maruf Yuldashev, MD, the member of the Immunomorphology Depertment study team. He has number of years of clinical experience, practicing gynecology and providing screening services for early detection of the cervical neoplasia. He is planning to conduct a comprehensive study on cervical neoplasia. His scientific interests in fundamental and apllied immunology.

Rano Sabitova, MD, MPH, is a public health specialist with extensive experience of the national health reform that currently joined the research team of the Institute of Immunology of the Uzbekistan Academy of Science. She is a graduate of the Tashkent State Medical Institute (MD, 1988) and the University of Arizona (MPH, 2006) She is cooperating with the study team of the Immunomorphology DPT as well for the research on the cervical ectopia. 


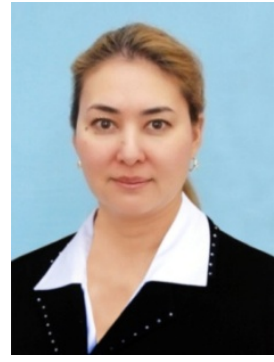

Gulnara Yangieva, MD, Candidate of Medical Science, is experienced obstetrician and gynecologist, the lecturer of Tashkent Medical Academia. She is collaborating with Immunomorphology Depertment of the Institute of Immunology on research concerning women's health/ cervical ectopia matters. Her scientific interests in applied immunology with special emphasis on women's cancers. 